\title{
EL ESTRIBILLO Y SUS VARIANTES EN LA POESÍA ESPAÑOLA DEL SIGLO XX NOTAS SOBRE SU CARACTERIZACIÓN Y TIPOLOGÍA
}

\author{
Ángel Luis LujÁn AtienZA
}

Resumen: El estribillo se caracteriza habitualmente por la repetición idéntica y regular de una fórmula, que constituye el tema del texto, al final de cada una de las estrofas de una composición poética. Esta definición presenta diversos problemas cuando la aplicamos a la práctica de la poesía del siglo Xx. El presente trabajo se ocupa de esta problemática en un doble sentido. Por una parte, propone, para la caracterización del procedimiento, un esquema semiótico que al incorporar simultáneamente rasgos de todos los niveles de significado permite definir el estribillo de manera más compleja y matizada. Por otra parte, se analizan varios ejemplos del uso del estribillo en poetas españoles del siglo xx en un intento de clasificación del procedimiento según sus rasgos diferenciadores. Para ello es imprescindible distinguir previamente entre poesía que se presenta como continuadora de la tradición popular (en términos amplios: poemas del género "canción") y poesía que contiene estructuras del tipo del estribillo sin ninguna vinculación con la estética tradicional.

Palabras clave: Poesía española del siglo xx, métrica, estribillo, figuras de repetición, poesía popular y popularizante. 
Abstract: The refrain is usually defined as the regular repetition of the same expression, the theme of the text, at the end of each stanza in a poetical work. This definition becomes problematic when applied to 20th century poetry. This paper deals with these difficulties in two ways. On the one hand, a semiotic model that takes into account features of all levels of meaning is proposed in order to characterize the metrical device in a more sophisticated and complex way. On the other hand, several examples of refrain in 20th century Spanish poetry are analysed in order to classify them according to their features. To do so, we need previously distinguish between a kind of poetry that continues the tradition (poetry belonging to the genre "song") and poetry that includes repetitions similar to refrains without link with the tradition.

Key words: 20th century Spanish poetry, metrics, refrain, repetition in poetry, traditional poetry, neotraditional poetry. 


\section{1.- ORigen, ETIMOlogía Y FUnCión DEL ESTRIBILLO}

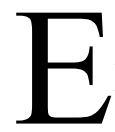

L procedimiento del estribillo es conocido desde las primeras manifestaciones líricas en forma coral. Tenemos testimonios de su existencia en la poesía arcaica griega y en los salmos hebreos, así como en las literaturas y ceremonias de otras civilizaciones, y todo apunta a que su práctica nace ligada a las letanías y cantos rituales y religiosos (Spyropoulou Leclanche, 1998: 5-20). Por esta técnica ancestral, a la voz del solista, que canta la estrofa, le sigue, complementa o responde el coro (la comunidad), que se hace cargo de la repetición de una fórmula o versos al final de cada estrofa. Sus diversas manifestaciones en todas estas culturas parecen apuntar a un universal en la forma de estructurar el material poético y melódico. Esta alternancia entre la voz individual y la participación de la colectividad está aún viva en nuestros días, por ejemplo en los conciertos de música pop en que el público corea los estribillos de las canciones o en diversas manifestaciones religiosas. En este uso primigenio y ancestral el estribillo tiene, pues, dos funciones: la de marcar el final de estrofa en el aspecto estructural, y ser una invitación a la participación coral en el nivel enunciativo.

Esta práctica recibe diversos nombres en las lenguas europeas, nombres cuyas etimologías nos dan idea de la diversidad con que se contemplan sus funciones. El "refrain" francés, que pasa al vocabulario inglés, procede del término del latín popular *Refrangere (<refringere $<$ frangere) que significa "romper" (Spyropoulou Leclanche, 1998: 20-27). Efectivamente, el fluir de la canción o la recitación se ve interrumpido 
o roto por la aparición periódica del estribillo. Curiosamente, de la misma palabra deriva nuestro "refrán", término en el que se ha perdido el sentido de ruptura y conserva el de brevedad y carácter sentencioso, rasgos que solían estar presentes en los estribillos, según nos recuerda Mayoral (1994: 215) con la autoridad de Díaz Rengifo: "ha de llevar algún dicho agudo y sentencioso". El prefijo "re-" da pie, además, en este caso a una falsa etimología que hace que relacionemos el término con la idea de repetición, que nos parece más natural al estribillo que la de ruptura. En cualquier caso, partiendo de esta etimología, se prima como criterio definidor el aspecto pragmático del procedimiento, en cuanto supone la ruptura de la continuidad de la voz solista. En la palabra inglesa "chorus", empleada también para denominar al estribillo, se prima igualmente el aspecto pragmático de participación coral.

El sentido de repetición es el que pone en primer plano la denominación italiana "ritornello", con un diminutivo que comparte con el término español "estribillo", de origen metafórico. En este no se insiste tanto en la repetición o en la ruptura como en la función estructural de organizar la composición: el "estribillo" es la fórmula en la que descansa o se apoya el texto para seguir adelante. En el Cancionero de Baena (1851: 12) se emplea la forma "estribote" para referirse al estribillo, como puede verse en la segunda composición de Villasandino, donde leemos: "su desfecha della por arte d'estrybote".

Domínguez Caparrós, en su Diccionario de métrica española (2004: 166) destaca principalmente estas dos funciones del estribillo como elemento de insistencia y base temática de la composición:

Si uno de los principios generales que caracterizan a la poesía es el de la repetición -base del ritmo-, el estribillo contribuye a la afirmación de este efecto rítmico y da unidad al poema. Su nombre, derivado de estribo, explica la función de base o tema en que estriba la composición, pues normalmente encierra la idea principal.

Partimos, pues, a partir de esta simple exploración en la etimología y en las denominaciones del procedimiento, de 
una serie de criterios iniciales para determinar la naturaleza y funciones del estribillo que van más allá de la mera repetición periódica creadora de ritmo, a la que estamos acostumbrados, y nos obligan a considerar otros aspectos: ruptura de la voz solista para marcar la entrada participativa del coro, apoyo para estructurar todo el material poético, base temática y carácter sentencioso (por su relación con el "refrán" español), principalmente.

\section{2.- El ESTRIBILLO ENTRE LAS FigURAS DE REPETICIÓN}

Al margen de sus diversas funciones en la composición poética, sobre las que después volveremos, el estribillo, en su aspecto formal, ha de incluirse dentro de los procedimientos de repetición que caracterizan a la lírica. La repetición, como procedimiento general, tiende a producir encantamiento e incluso arrobamiento más allá del placer:

El radical del melos es el encantamiento (charm): el conjuro hipnótico que, mediante su ritmo pulsátil de danza, provoca una reacción física involuntaria y que, por lo tanto, no está lejos del sentido de la magia o poder físicamente compulsivo. Adviértase que la ascendencia etimológica de "charm" (encantamiento) remonta a carmen, canción. Los encantamientos reales poseen una cualidad que la literatura popular imita en las canciones de trabajo de toda suerte y especialmente en las canciones de cuna en que la repetición amodorrada que induce al sueño pone de manifiesto con toda claridad el patrón subyacente, oracular u onírico. La invectiva o 'dimes y diretes', imitación literaria de la maldición por conjuro usa similares recursos de sortilegio por razones opuestas (Frye, 1991: 368).

Entre las diversas modalidades que adopta la repetición en el lenguaje lírico, el estribillo tiene relación con todas aquellas que marcan un límite estructural y preferentemente con aquella que indica final de serie y que conocemos genéricamente con el nombre de epífora. Los manuales de oratoria, además de definirla, nos enseñan que se usa normalmente con la intención de insistir, como recuerda Quintiliano, en su 
Institutio Oratoria $(9,3,30)$ : "Et ab iisdem verbis plura acriter et instanter incipiunt [...] et iisdem desinunt", y como muestran los ejemplos que trae la Rhetorica ad Herennium (Cicerón, 1991: 267), del que extraigo este:

Nam cum istos, ut absolvant te, rogas, ut peiurent, rogas, ut exeistimationem neglegant, rogas, ut leges populi Romani tuae libidini largiantur, rogas.

Esta figura es complementaria de la anáfora que sirve también para expresar insistencia, y cuando se dan juntas constituyen la complexio, forma de paralelismo extremo, como en el ejemplo que aporta Lausberg (2003: § 633):

Quis legem tulit? Rullus; qui tribus sortitus est? Rullus; quis decemviros creavit? idem Rullus

Anáfora y epífora marcan los límites estructurales de partes dentro de un discurso, sin embargo, la flexibilidad y perceptibilidad de la epífora, al ser señal de cierre, son mayores que las de la anáfora. La epífora, además, introduce un elemento de previsibilidad y es, por tanto, una invitación a que el oyente se una a la enunciación. En el ejemplo clásico que acabamos de ver de la acusación contra Rulo observamos cómo el orador parece estar invitando al público a que repita con él al final de cada periodo "Rulo".

Esta afinidad formal, funcional y estructural entre la epífora y el estribillo hizo que los tratadistas llegaran a considerar al estribillo como una manifestación de la epífora, según se ve en Jiménez Patón (1604: 36-37):

Conversión en Griego Anastrophe es quando se repite la palabra misma en los fines de los miembros como en esta letrilla se hallan dos conversiones interpoladas una en esta palabra. Bien puede ser, otra. No puede ser [se incluye aquí la letrilla de Góngora]. Es exemplo tambien de esta figura la letrilla que cierra el sentido de cada quarteta con esta palabra abrenuncio. Sonlo todos los Romances que acaban sus coplas en un final que dizen estrivo, y todas las coplas assi octavas como Liras, redondillas o quintillas, que glossan muchas veces un mismo verso que dizen Pie, sonlo todos los villancicos en retruecano. 
Existe, pues, una tradición retórica que identifica la epífora o conversio con el estribillo, que llega incluso hasta nuestros días, pues Henri Morier, en su Dictionnaire de Poétique et de Rhétorique (1998: 459), no reserva una entrada específica para "estribillo", sino que lo incluye como una modalidad de la Epífora.

Podemos, además, poner el estribillo en relación con otra modalidad de la epífora que afecta a unidades menores, en concreto a la repetición de sonidos finales: la rima. Cabe pensar que la aparición de la rima en las literaturas romances y el latín vulgar nace como una forma de marcar el final de verso una vez que se ha perdido la métrica cuantitativa y tonal. Méndez Bejarano (1907: 344-345), de hecho, explica de esta manera su aparición. Según él, cuando cae el sistema cuantitativo de la métrica latina, se pasa a un sistema basado en la acentuación tónica; pero como esto no resultaba suficiente para apreciar el ritmo, se hizo necesario agregar otros elementos de armonía: "Buscóse entonces una relación literal $\mathrm{y}$, a título de inconsciente ensayo, asomó la aliteración, cuya sencillez recuerda el paralelismo primitivo". La aliteración, como reflejo en el nivel silábico de la anáfora, fue adoptada principalmente por las literaturas anglosajonas y escandinavas. Con todo, este nuevo elemento de armonía resultaba demasiado tenue para el oído y obligaba a aproximar las palabras aliteradas, lo que hacía la escansión monótona y poco variada. Finalmente, "tan legítimas causas, unidas al desenvolvimiento creciente de la música, hicieron que la aliteración pasara a las consonantes finales del verso, dibujándose así la rima que no debía tardar en aparecer". De hecho, la rima acaba prevaleciendo, e incluso las literaturas que basaban su ritmo en la aliteración la adoptaron.

Independientemente de que la historia y evolución hacia la rima tuviera lugar así o no, lo que está claro es que la aliteración (inicial) y la rima (final) constituyen dos soluciones diversas al problema de marcar los límites estructurales y de crear ritmo y melodía. El triunfo final de la rima parece deberse a causas que puede explicar la psicología de la percepción, como el simple hecho de que las posiciones finales de 
toda serie siempre son más perceptibles y memorizables. $\mathrm{Si}$ la anáfora y las figuras por repetición que se sitúan en los inicios de serie suelen estructurar el desarrollo de los textos, las figuras que se sitúan al final (epífora, rima, estribillo), además de contribuir a la estructura, tienen una función enfatizadora, sirven para poner de relieve aquello en lo que se debe insistir y retener en la memoria, e introducen un elemento de previsibilidad en la serie del recitado o el canto.

\section{3.- CRiterios PARA EL ESTUdio Del ESTRIBILLO Y SU DIVERSIDAD}

Una vez vistas las características que el estribillo hereda de su pertenencia a las figuras de repetición en final de serie, tomemos como punto de partida algunas definiciones iniciales del estribillo que responden a una descripción prototípica del procedimiento:

Expresión o cláusula en verso, que se repite después de cada estrofa en algunas composiciones líricas, que a veces también empiezan con ella $(D R A E)$.

Breve grupo de versos que sirve de introducción a una composición y que se repite total o parcialmente después de cada estrofa. El zéjel, la letrilla, el villancico y, a veces, el romance son clases de poemas que llevan estribillo. También se encuentra con otras formas de poesía popular (Domínguez Caparrós, 2004: 165).

José Antonio Mayoral (1994: 214-217), por su parte, lo vincula con la glosa, ambos incluidos en lo que él llama "equivalencias textuales vinculadas a ciertas formas estróficas". Mayoral destaca dos características del estribillo: "La función de 'generador textual' desempeñada normalmente por la unidad estribillo, en su doble condición de unidad de contenido y unidad estrófico-formal", que coincide con uno de los rasgos que hemos visto, y "la asignación de unos lugares fijos a la repetición, ya del estribillo en su totalidad, ya de segmentos -generalmente finales-del mismo" (1994: 214). 
Vemos que todas las definiciones insisten sobre todo en el carácter repetitivo del procedimiento. Mayoral, al emparentarlo con la glosa, se hace eco además de su función pragmática, pues tanto el estribillo como la glosa suponen la inclusión de una voz ajena en las composiciones y un efecto de polifonía.

Son definiciones todas ellas que cuadran perfectamente para el estribillo tal y como se usa principalmente en el Siglo de Oro, cuando la fórmula no sólo se repetía al final de las estrofas sino que generalmente encabezaba la composición, dictando el tema y la métrica de todo el texto, en su función de cabeza o tema (Mayoral, 1994: 215). Esta va a ser una de las características con las que rompe el siglo $\mathrm{xx}$, pues raramente el estribillo hace de cabeza (y por tanto tampoco de tema y patrón métrico) ${ }^{1}$ y más raramente aún se toma el estribillo de la tradición popular o de algún otro autor. El estribillo suele ser de invención propia, con lo que se atenúa la función coral o de responsorio que compartían el estribillo y la glosa.

La repetición regular y periódica de una misma fórmula, en la que insisten estas definiciones, ha de ser igualmente matizada como definitoria del estribillo cuando lo estudiamos en el siglo $\mathrm{xx}$, pues nos encontramos, como veremos, con composiciones fuertemente irregulares en su distribución estrófica e incluso en las que ha desaparecido todo sentido de estrofa.

Pero no todas las excepciones a estas definiciones proceden de las innovaciones de la poesía del siglo Xx. Podemos empezar señalando el hecho de que en sus manifestaciones más genuinas en la poesía popular, tal y como vienen recogidas en el corpus de Margit Frenk (1990), no se puede hablar

- Esta característica la señala también Mario GARCÍA-PAGE como propia del estribillo en el siglo xx: "Tal estribillo ya no funciona siempre como señal de apertura del texto, como el villancico popular, pues puede aparecer en medio del poema o después de cada estrofa, ni necesariamente cierra el poema" (GARCIA-PAGE, Mario: "Un fenómeno de repetición textual: el estribillo en Emilio Prados". Estudios de Lingüística de la Universidad de Alicante, 2003, 17, p. 308). Aunque después vemos, en su estudio sobre el estribillo en Prados, que éste respeta en diversas ocasiones la norma popular de hacer del estribillo cabeza de la composición. 
en sentido estricto de repetición periódica, pues en ellas el estribillo encabeza el poema y lo cierra, ocupando el centro de la composición un desarrollo sobre la idea presentada en la cabeza. Al no existir más que una estrofa, el resultado se parece más a una estructura circular que a una composición basada en la repetición insistente de un tema.

Otro problema con respecto al estribillo que no es privativo del siglo $\mathrm{xx}$, sino que se encuentra ya en las composiciones medievales y de los Siglos de Oro, es el hecho de que en muchas ocasiones la repetición del estribillo no es exacta. La variación es un factor habitual dentro de los procedimientos para crear ritmo con el fin de romper la monotonía y el automatismo de la respuesta. El problema es que la perceptibilidad del estribillo depende en gran parte de su previsibilidad, garantizada por la repetición exacta. Introducir alguna variación léxica o de entonación no impide, desde luego, la percepción del procedimiento, pero ¿hasta dónde debe llegar el grado de similitud para poder seguir considerando que se trata de un estribillo?, ¿hasta dónde llevamos el límite de la variación? $^{2}$

En cuanto a la brevedad de la fórmula que se repite, otro rasgo definitorio del estribillo, ello implica que el estribillo debe contrastar con el cuerpo del poema por su menor extensión. El problema se presenta aquí cuando aparecen elementos cuya repetición ocupa tanto como las estrofas. Tenemos un ejemplo en la "Canción primera" de Blas de Otero en Que trata de España (1964: 89). El estribillo, que aparece como cabeza, está compuesto por dos versos que varían en su repetición de manera alterna "Esperanza, camino / bordeado (ladeado) de mirtos". Lo que nos interesa destacar ahora es que el poema está compuesto exclusivamente por dísticos y la repetición del pareado que forma el estribillo (que rima con el último verso del dístico que lo precede), lo que significa que el estribillo ocupa tanto espacio como el cuerpo de la composición y deja de existir contraste por extensión entre estrofas y repetición. Un caso extremo de desproporción entre

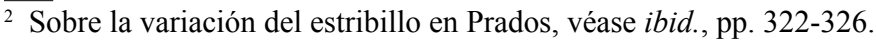


estribillo y cuerpo de la composición lo tenemos en los ejemplos de Prados que aduce García-Page (2003: 311-313).

Del mismo modo, plantea problemas la aparición del estribillo en un poema de tipo paralelístico, lo que García-Page (2003: 320-321) denomina "epímone múltiple", pues la repetición que aparece al final de las estrofas apenas puede considerarse estribillo en sentido estricto en la medida en que el procedimiento forma parte de una estructura más amplia, basada en el paralelismo. José-Miguel Ullán (2008: 534), en Manchas nombradas, incluye un poema que después de una entrada, repite cada dos versos: "joh, armaduras abandonadas". El resto de los versos mantiene la misma estructura: "Entre x e y". Lo mismo ocurre en "Un anillo en el mar", de En el otro costado, de Juan Ramón Jiménez (1999: 63).

El problema de la percepción o no del estribillo va ligado al de la regularidad o irregularidad de las estrofas y a la periodicidad fija o no de la repetición. Siguiendo con Juan Ramón Jiménez (1999: 212-213), vemos el poema "Primavera 63 (Con ella y sin pájaro)" de Una colina meridiana, formado por tres estrofas de extensión amplia pero irregular que tampoco guardan proporción alguna en los versos ni tienen rima. Al final de cada una de las tres grandes estrofas aparece una repetición con variaciones: "hacia el poniente grana y amari1lo", "hacia el poniente azul y platecido" y "contra el poniente grana y amarillo". Aunque el sentido de repetición insistente está claro, sin embargo, la repetición no cumple otros criterios del estribillo, y, más que un compendio semántico de la composición o una invitación a la participación coral, se trata de marcar el paso del tiempo a lo largo del poema.

El mismo problema de repetición con irregularidad periódica y variación encontramos en Alberti (1988a: 538-539) en el poema "Los niños de Extremadura", de El poeta en la calle, donde, después de cada estrofa de carácter irregular, hay una pregunta que varía, pero que tiene la misma estructura sintáctica: “QQuién les + verbo en pasado + OD?”, excepto la última, que tiene verbo copulativo.

Otro problema específico de las manifestaciones del estribillo en el siglo xx lo tenemos cuando el estribillo se incluye 
periódicamente dentro de un poema en prosa, como ocurre en "El país del sol” de Rubén Darío (2008: 180-181).

Estas son algunas de las cuestiones que plantea el estudio del estribillo en la poesía contemporánea, y en las que después entraremos con ejemplos concretos. Para comprender mejor estos fenómenos, debemos establecer una serie de criterios más complejos para el estudio del procedimiento. Aparte de caracterizar al estribillo por las funciones que hemos visto, y por los rasgos que nos ha legado la tradición, debemos tener en cuenta una caracterización semiótica como la que hace Spyropoulou (1998). Aunque pensada en principio para la canción francesa, los criterios de Spyropoulou son aplicables a todo poema que use el estribillo, pues los mecanismos son los mismos.

Distingue la autora francesa en principio dos tipos de estribillo: el estribillo suelto o separado (con variación o sin variación) y el estribillo integrado. Este es un primer criterio de clasificación que tiene importantes implicaciones, pues el estribillo separado suele tener menos relación con el cuerpo de la composición que el estribillo integrado ${ }^{3}$. Seguidamente, Spyropoulou estudia los elementos de ruptura (según la tradición de la etimología francesa) en lo que atañe a la métrica y la enunciación, la organización interna del estribillo y su semántica. Todos estos criterios se pueden reconsiderar desde el punto de vista semiótico, siguiendo el espíritu de esta propuesta, agrupándolos en lo que afecta a cada uno de los planos de significación, y teniendo en cuenta que cada uno de estos niveles hay que estudiarlo desde una doble perspectiva: la que afecta a la estructura interna del estribillo y la relación del estribillo con el conjunto del texto al que pertenece y más en concreto con cada una de las estrofas que le preceden. Es decir, en cada nivel de significado hay que considerar la estructura interna del estribillo y su relación externa con el resto de la composición. Esto da el siguiente esquema de criterios que aquí simplemente esbozo:

Sobre el estribillo separado o no tipográficamente de las estrofas véase, ibid., pp. 316-318. 
1. Nivel morfosintáctico:

a. Estructura interna: forma métrica y organización interna (tipo de oración, extensión, etc.); identidad o no del estribillo durante toda la composición; presentación gráfica (normal, entre paréntesis, en cursiva); etc.

$b$. Estructura externa: estribillo exento o no; funciona como cabeza o no; continuidad o no con la sintaxis de la estrofa que le precede; coherencia o no con la forma métrica del resto del poema; existencia o no de rima con la estrofa; etc.

2. Nivel semántico:

a. Estructura interna: organización semántica interna; carácter de los elementos léxicos; estribillos con sentido, sin sentido, puro sonido, etc.

$b$. Estructura externa: relación con la semántica del resto del poema o de cada una de las estrofas; base temática o no del poema.

3. Nivel pragmático:

a. Estructura interna: tipo de enunciado del estribillo; de autoría propia o ajena.

$b$. Estructura externa: relación enunciativa con el resto del poema; cambio de enunciador, carácter coral, etc.

\section{4.- El estribillo en el Siglo XX}

Como hemos ido apuntando, el estribillo en el siglo xx tiene características propias que lo diferencian de su uso en épocas anteriores y del uso que ha hecho siempre de él la poesía genuinamente popular. La revitalización del estribillo en el siglo xx tiene que ver en España con el neopopularismo que caracterizó a una corriente de la generación del 27, que venía precedida por las composiciones de Juan Ramón Jiménez y Antonio Machado. Como los vihuelistas y poetas 
de los siglos XVI y XVII, se trata de autores cultos que imitan formas populares, pero mientras que aquellos tomaban, como base temática y melódica para su composición, el estribillo de un villancico popular o de otro autor, los autores contemporáneos suelen ser autores de sus estribillos, incluso cuando imitan las formas populares. Además, al no existir la parte musical, los autores usan el estribillo de manera más flexible, pues este ya no tiene que dar la pauta métrica y melódica a toda la composición.

La relación del estribillo con la poesía popular es clara incluso en autores de la estética de vanguardia. Gerardo Diego en su libro Imagen hace una pequeña reflexión sobre el estribillo como introducción a una parte llamada precisamente así: "Estribillo" (1989: 137). Diego relaciona el estribillo con la musicalidad y habla de "ensayos más musicales que plásticos, dejándose ir cauce abajo en un deleitoso entresueño cerebral", donde encontramos la idea del encantamiento como efecto de las repeticiones rítmicas. El tipo de poesía que Diego incluye aquí se identifica como "Poesía de vacaciones cantada entre siestas perezosas y lejanos ritornelos infantiles". Es decir, el estribillo tiene que ver con todo lo infantil, ingenuo, espontáneo: "Estribillos, repetidos o no, que aun éstos quisieran serlo por su ingenua espontaneidad involuntaria". No sabemos exactamente qué quiere decir Diego con "repetidos o no".

Por otra parte, el primero que reflexiona sobre el estribillo en la poesía culta moderna es Edgar Allan Poe, que, en su Philosophy of composition, presenta el refrain de su poema "The Raven" como un pivote o elemento estructural y temático que ha de organizar todo el poema, que coincide con una de las funciones tradicionales asignadas al estribillo. De hecho, su estribillo de una sola palabra "Nevermore" ha pasado al repertorio de palabras fetiche de estéticas como el simbolismo francés o el modernismo español (piénsese en los poemas de Antonio Machado titulados "Nevermore"). Consigue con ello Poe no sólo concentrar el sentido de su poema en una expresión sumamente sintética, sino también dar un lema a toda la poesía de la modernidad, un estribillo para toda una estética. 
Poe considera que el efecto de repetición insistente, aunque pretendido en su poema para transmitir la obsesión del recuerdo y de la pérdida, no justifica de manera suficiente el uso del viejo procedimiento. Poe, de acuerdo con la tradición de la modernidad, quiere que el uso del estribillo esté motivado por algún tipo de verosimilitud estética y no sea un mero expediente arbitrario, de adorno o exigido por la musicalidad, como solían ser los estribillos populares y tradicionales, según hemos visto caracterizados por Diego. Poe ve en el estribillo tradicional el problema de su monotonía y la falta de matices, $y$, en consecuencia, pretende que a cada nueva aparición la palabra-estribillo que ha elegido alcance significados o tonalidades nuevas:

I resolved to diversify, and so vastly heighten, the effect, by adhering, in general, to the monotone of sound, while I continually varied that of thought: that is to say, I determined to produce continuously novel effects, by the variation of the application of the refrain -the refrain itself remaining, for the most part, unvaried (2002: 42).

También se plantea Poe en esta línea cómo hacer creíble la repetición monótona de la misma palabra, lo que le lleva a descartar a un interlocutor humano y elegir a un cuervo como su enunciador. De manera que en Poe detectamos algunos de los problemas que plantea el estribillo en la modernidad. El autor quiere retener el sentido de repetición generadora de ritmo con el efecto de insistencia obsesiva y su carácter de pivote de toda la composición, pero renuncia a hacerlo como un mero procedimiento sonoro o repetitivo desprovisto de sentido. El gran problema que plantea Poe, entonces, es el de motivar enunciativamente el estribillo y el de hacer de él un generador de sorpresa poética, lo que rompe con el sentido de previsibilidad que le asignaba la tradición.

Es necesario, pues, a partir de aquí, distinguir, dentro del uso del estribillo en el siglo $\mathrm{xx}$, entre dos tendencias: la que sigue más o menos la estética tradicional y popular, que no busca justificar la presencia de este procedimiento y se apoya simplemente en la tradición de su uso, y la que incluye el 
estribillo en estructuras que no son tradicionales ni populares y que, por tanto, pretende otros efectos o nos hace replantearnos la naturaleza entera del estribillo en este tipo de composiciones.

Hay que entender, no obstante, que los autores que siguen el modelo tradicional lo hacen con mucha más flexibilidad y libertad que los creadores (conocidos o anónimos) a los que imitan o siguen, pues están inevitablemente en la órbita de las reflexiones de Poe y la práctica de otros autores de la modernidad.

\section{5.- El estribillo en la poesía POPULARIZANTE DEL SIGLO XX}

Dentro de la poesía popularizante del siglo xx podemos encontrar estribillos a la manera de la canción tradicional donde una misma fórmula se repite idéntica al principio y final de la composición, quedando en el centro un pequeño desarrollo. Este estribillo está separado del cuerpo principal y tiene una función básicamente estructuradora, pues supone la base semántica sobre la que se desarrolla la estrofa central. Tenemos un buen ejemplo en el poema de Alberti "Desde alta mar" de Marinero en tierra (1988a: 132-133), donde el estribillo "No quiero barca, corazón barquero, / quiero ir andando por la mar al puerto" presenta el tema que desarrolla de manera imaginativa el cuerpo de la canción. Como ya he señalado, este tipo de repetición plantea el problema de que constituye más un marco de la composición que un estribillo propiamente dicho, pues le falta el sentido de insistencia y de participación coral: como vemos aquí la segunda aparición supone un refuerzo de la voz que ha iniciado el poema. Esta única repetición, además, no es bastante para crear un ritmo perceptible, y en este caso ni siquiera métricamente el estribillo condiciona el desarrollo de la estrofa, pues, al contrario de lo que ocurre con la canción tradicional, está compuesto de dos endecasílabos y la estrofa central son cuatro octosílabos, aunque marca el timbre de la rima, asonante en -é-o. 
En el libro Canciones, de Luis Rosales (1996: 407), del año 1973, lejos ya de la época neopopular, encontramos un texto con estribillo a la manera tradicional, "Canción del dímelo de una vez", con la vuelta al segundo verso del estribillo al final, enmarcando el poema.

Esta repetición única constituye el límite inferior del estribillo debido a su escasa perceptibilidad. La forma que consideramos prototípica del estribillo y en la que se centran principalmente las definiciones que hemos visto: repetición idéntica al final de cada una de las estrofas de una composición, lo que da pie a villancicos y zéjeles, es difícil de encontrar en su forma pura, pues el siglo xx busca la variación y la sorpresa. No obstante, observamos alguna muestra como la parte II del poema de Alberti, "El mar muerto" de Marinero en tierra (1988a: 130), con un estribillo de dos versos que conserva el aire popular, aunque es obra del autor: "No lo sabe nadie, nadie. / ¡Mejor, si nadie lo sabe!”. Se trata de un estribillo exento con respecto a la estrofa y que guarda clara relación semántica con el resto del poema, pues trata de la ignorancia de la muerte del mar. Aquí podemos ver articulación pragmática dentro del estribillo mismo, porque ocurre como si una voz reafirmara a otra.

El alba del alhelí (Alberti, 1988a: 276-277) contiene un poema con estribillo también de tipo clásico, el autorretrato burlesco "El tonto de Rafael". Se trata en realidad de un villancico tradicional, compuesto por una cabeza de dos versos y cuatro quintillas con un verso de vuelta que rima con el estribillo, exento tras cada estrofa. El estribillo, pues, estructura métricamente la composición, aunque en lo que respecta a la semántica supone un elemento de ruptura, pues si bien es verdad que concentra el sentido del autorretrato burlesco sin embargo no se relaciona directamente con las estrofas que le preceden. Se trata, además, de un estribillo que tiene articulación enunciativa interna, con una estructura de preguntarespuesta: “¿Quién aquel? / ¡El tonto de Rafael”. La última repetición incluye una variante, probablemente como marca de final de poema y no sólo de final de estrofa. 
Lo mismo ocurre en el famoso poema "Si Garcilaso volviera" (Alberti, 1988a: 143), que conserva cierta estructura de villancico, pues de la cabeza se repite el último verso tras cada una de las dos estrofas: "que buen caballero era", inserto dentro de la estrofa, y, sin embargo, no tiene una relación semántica directa ni morfosintáctica con ellas, como sí la tiene en la primera aparición en la cabeza.

En la obra de Luis Rosales encontramos, sobre todo en su primera etapa, ejemplos del uso del estribillo a la manera tradicional. La parte 5 de "Poema del aprendiz y el discípu1o" (1996: 154-155) está escrita en cuartetas asonantadas con rima en los versos pares; todas las cuartetas acaban con el verso "Misericordiosamente". Se trata de un estribillo de una sola palabra que tiene relación sintáctica con cada una de las estrofas, pues es el adverbio que complementa cada verbo.

En el libro En el otro costado, de Juan Ramón Jiménez (1999: 89), el poema "No quiero lo demás" está compuesto por estrofas de tres versos no isométricos. El estribillo: "¿qué me falta?" forma parte de la estrofa y rima en asonante con el verso anterior. También semántica y enunciativamente tiene relación con las estrofas, pues la insistencia en la pregunta procede de lo planteado en cada una de ellas, y conserva algo de invitación a la participación coral, o, al menos, su previsibilidad es muy alta.

Frente a estos estribillos de repetición idéntica y que sirven de patrón métrico y temático a la estrofa, podemos comprobar que lo que más abunda son estribillos que introducen alguna variante sobre este esquema. En un primer caso, la variante procede de la dependencia del estribillo de la sintaxis de la estrofa. En el poema de Alberti "La niña que se va al mar" (1988a: 144) el estribillo, aunque gráficamente exento en relación con el cuerpo de la canción, muestra su dependencia de la sintaxis de la estrofa, pues en cada ocasión varía al pronominalizar un elemento de dicha estrofa: parte del cuerpo o prenda. También pragmáticamente tiene que ver con las estrofas pues se trata de un ruego o una advertencia que deriva de lo dicho en la estrofa. 
Otro de los motivos para introducir una variante en el estribillo es hacerlo solo en la aparición final para señalar el cierre de composición y no solo de estrofa. Eso ocurre en el poema 25 de la serie "Toro en el mar" de Entre el clavel y la espada (Alberti, 1988b: 109), donde aparece un estribillo repetido e idéntico, con la peculiaridad de que que en la última estrofa la afirmación se vuelve interrogación, así que la marca de final en este caso implica un cambio en el nivel enunciativo del estribillo.

Este ejemplo nos sirve, además, para introducir otra peculiaridad del estribillo en el siglo xx: la aparición del estribillo entre paréntesis. Que yo sepa, la poesía tradicional nunca recurría a este expediente, y el que lo usen los autores contemporáneos tiene que ver con la sensación de ruptura que hemos visto que introduce el procedimiento, pues es como si se quisiera con ello recalcar el carácter marginal, la excepción a la línea poética, que supone el estribillo. Aparece este fenómeno en el primer Lorca del Libro de poemas, en concreto en "Consulta" (96-97), donde se repite el dístico: "( $¡$ Oh poeta infantil, / Quiebra tu reloj!)", que supone una ruptura con el resto de la composición no sólo por aparecer entre paréntesis, sino porque ni métrica ni semánticamente tiene que ver con el resto de la composición, pues mientras que las estrofas riman en asonante -ó-a, el estribillo no tiene rima, y mientras que las estrofas son apelaciones a objetos (pasionaria, estrella, corazón) que guardan un claro paralelismo, el estribillo se dirige al poeta mismo, así que con el paréntesis se quiere indicar que la enunciación ha saltado un nivel y se ha convertido en metapoética. Curiosamente después de la repetición tras tres estrofas, el poema finaliza con una tirada de versos de carácter no estrófico.

Igualmente entre paréntesis encontramos un estribillo en "Balada interior" (García Lorca, 2005: 103-104) que presenta varias peculiaridades, además del paréntesis. En primer lugar, se trata de una cita de una fórmula popular, que varía, pues tras las tres primeras estrofas se lee: "(Frío, frío, / Como el agua / Del río.)", y tras las tres siguientes aparece la fórmula contrastante perteneciente al mismo juego: "(Caliente, 
caliente, / Como el agua / De la fuente.)". Su carácter de cita, es decir, el salto en la enunciación que veíamos en el ejemplo anterior, podría justificar el uso del paréntesis, pero esta explicación no cuadra con el hecho de que ambas fórmulas son respuesta a una misma pregunta que, como un estribillo, cierra cada una de las estrofas: “¿Está en ti, / Noche negra?”, con relación semántica y sintáctica con cada una de las estrofas, y que rima en asonante con algún verso de ellas. Así pues, tenemos una composición con doble estribillo, uno fijo dependiente de su estrofa desde el punto de vista semántico, sintáctico y métrico, y otro que varía, entre paréntesis, exento y que constituye una respuesta al primer estribillo citando fórmulas de un conocido juego infantil. Para complicar más las cosas, el poema no se cierra con la última aparición del estribillo, sino que añade un dístico que poco tiene que ver con el resto, final que viene adelantado por el hecho de que en su última aparición el estribillo estrófico introduce una variante: “Es cierto, / Noche negra?”, con lo que tenemos multiplicadas las señales de cierre.

También entre paréntesis está el estribillo de "Primer nocturno del cuco" (García Lorca, 2005: 230), en el que el dístico "(Sólo el cuco / permanece.)" se repite idéntico y exento tras cada dístico con el que no tiene relación métrica. El paréntesis indica en este caso sólo el contraste entre la indecisión y pérdida y la permanencia del canto del cuco. Este estribillo sirve para reforzar la idea de insistencia de ese canto y lo presenta como una excepción al ambiente de pérdidas de la noche. Este poema, además, plantea el problema de si podemos considerar esta repetición estribillo, pues no se cumple la norma de contraste de extensión entre estribillo y cuerpo del poema, pues al ser una sucesión de dísticos, el estribillo ocupa tanto como las estrofas.

Para seguir explorando los estribillos con variantes, veamos algunos poemas de Alberti. El primero es "Yo te hablaba con banderas" de Marinero en tierra (1988a: 133), cuyo estribillo se repite dos veces, pero en orden inverso. Se trata, además, de un estribillo exento que no tiene relación semántica con el resto de la composición, aunque sí rima en asonante 
con algún verso de la estrofa. "Madrigal dramático de ardiente-y-fría" (1988a: 113) tiene un estribillo de dos versos en el que el primero permanece "El niño aprendiz de sastre," y el segundo cambia en cada aparición, sin que la variante tenga relación aparente con la estrofa, excepto en el primer caso: "¡cómo la deshojaría!", pues se ha calificado a "Ardiente-yfría" de "clavel"; y en la aparición final como una marca de cierre, pues el esquema que se venía repitiendo: "le ofrece una + nombre de flor" se convierte en: "le da una manzana, muerto". En "Si Lope resucitara" de El poeta en la calle (A1berti 1988a: 539-540) Alberti toma el estribillo de un verso del Fénix, en uno de los pocos casos que se nos presentan de estribillo ajeno. El poema adopta la forma de villancico tradicional, con la repetición como parte de la estrofa y con rima con el verso de vuelta. Enunciativamente la repetición está motivada porque tanto en las estrofas como en ella, se pide al lector que siegue, con una variante: en el primer caso aparece el estribillo como "Ten y siega, / que la hoz es nueva", y en los siguientes como "Siega, siega/ que la hoz es nueva". La razón es lógica: primero hay una entrega del instrumento y después una insistencia en su uso. Esto es raro porque suelen ser los finales de poemas los que se marcan con una variante y no los principios.

Un caso de alteración del segundo verso del estribillo que hemos visto en Alberti lo tenemos también en Gerardo Diego (1989: 385-386), dentro de Poemas adrede, en el texto titulado "Negro humor", imitación de las formas populares. Las estrofas son regulares (cuartetas aaba) y el estribillo rima con el verso tercero de cada estrofa (bb), excepto en la última. El estribillo viene en la cabeza, cosa rara en el siglo xx; consiste en un pareado cuyo primer verso es siempre el mismo: "Oh la melancolía" y varía el segundo. Estas variaciones van en contra del principio de previsibilidad que debe regir todo estribillo, además de que la relación semántica con el resto del poema es bastante distendida, en un intento de introducir el absurdo y la incoherencia dentro de la estética tradicional.

Una variante que ya se daba en la tradición es la aparición del estribillo alterno, como tenemos en el famoso poema de 
García Lorca (2005: 279-280) "Baladilla de los tres ríos", de claro corte popular.

En todos estos casos de estribillo con variantes (he espigado solo unos casos, se pueden aducir muchos más) habría que pensar no tanto en un estribillo que cambia, como en el hecho de que cada una de las apariciones es la manifestación visible de una forma arquetípica y latente, que nunca se materializa, del estribillo ideal.

Vamos a listar ahora una serie de ejemplos de estribillos cuya falta de motivación conduce finalmente al sinsentido o a la pura forma musical desprovista de valor semántico. Aquí la independencia del estribillo afecta principalmente al nivel semántico y pragmático. En Libro de poemas de García Lorca (2005: 94-95) aparece un poema titulado "Madrigal", cuyo estribillo, exento, sin rima ni relación sintáctica con las estrofas, tampoco tiene ningún lazo semántico aparente: "El fondo un campo de nieve". Es una información que nada tiene que ver con el resto del poema, a no ser que establezca un contraste entre la pasión que se encierra en las estrofas y la frialdad de fondo que pone la imagen de la nieve. Además, se marca el cierre del poema con una variante: "Y el fondo es un campo de nieve".

Gerardo Diego, en la sección "Canciones" de Versos humanos (1989: 280), incluye un poema (el número 27) que imita la poesía popular, aunque por el lenguaje se aproxima más a la vanguardia; las estrofas están formadas por cuatro versos heptasílabos con rima consonante los pares. Detrás de cada estrofa encontramos la repetición de un estribillo en cursiva, sin rima ni relación sintáctica con la estrofa, pues va exento y separado por un punto: "Tú oblicua". El hecho de que el estribillo esté en cursiva nos recuerda a los estribillos entre paréntesis, y lo único que podemos establecer es una relación semántica de contraste, como acabamos de ver en el poema de Lorca, pero aquí de manera más clara, pues el poeta contrapone la verticalidad $\mathrm{u}$ horizontalidad del mundo a la oblicuidad del tú. Este tipo de estribillos de relación semántica contrastante nos hacen reflexionar sobre el hecho de que el estribillo en el siglo xx pierde su función de ser base 
temática de la composición y, a cambio, establece una tensión semántica interna en el poema, con una relación de oposición al texto principal.

En este ámbito de los estribillos de clara ruptura y falta de motivación encontramos el formado por una sola palabra. En el poema "Jardinero", de Rafael Alberti (1988a: 105-106) tenemos tres estrofas regulares, tercerillas en concreto, $y$, tras cada una, separada por un punto y con rima con algún verso de la estrofa, aparece la palabra "Jardinero". Se trata de un caso claro de ruptura de la continuidad del poema, pues, si leyéramos las estrofas sin el estribillo, formarían una sucesión sintáctica y semántica perfecta. Se trata, pues, de un estribillo intercalado, que además no tiene relación con el resto, pues podemos pensar en un vocativo, aunque el sentido es afirmativo.

Siguiendo por este camino de los estribillos inmotivados, llegamos a otra variedad especialmente presente en la tradición popular infantil: el estribillo sin sentido, formado por el puro sonido ${ }^{4}$. Lo vemos en Libro de poemas, de García Lorca (2005: 87), en el poema "Noviembre", que usa como estribillo la onomatopeya: "Tin / Tan, / Tin / Tan", que ni siquiera rima con las estrofas, aunque aparece contiguo a ellas. Se trata de un estribillo de semántica vacía.

\section{6.- El estribillo en la poesía no POPULARIZANTE DEL SIGLO XX}

Si en la poesía popularizante, a pesar de las variantes y novedades, existe una continuidad con los mecanismos tradicionales, la aparición de estructuras del tipo del estribillo en la poesía que no pretende ser heredera de lo popular presenta problemas distintos, pues supone fundir dos sistemas poéticos distintos. Es lo que planteaba Poe a la hora de reflexionar

$\overline{4}$ Sobre el estribillo en la poesía popular infantil en relación con la creación de ritmo y las estructuras repetitivas, véase CERRILLO, Pedro C.: "Poesía y Escuela: reivindicación de la poesía infantil”. Letras Peninsulares, 2007, 20.1, pp. 236-239, y en particular para el género de las canciones de cuna: CERRILLO, Pedro C.: La voz de la memoria (Estudios sobre el Cancionero Popular Infantil). Cuenca: Universidad de Castilla-La Mancha, 2005, pp. 52-53. 
sobre la motivación y la naturalización del estribillo en la poesía culta no tradicional.

Independientemente de su relación directa o no con la tradición está claro que el estribillo se asocia casi de manera necesaria a las estructuras poéticas propias del género canción, aunque esta se reelabore de manera culta. No olvidemos que el procedimiento nace unido al canto y la recitación pública, con participación del auditorio. ¿Qué ocurre, entonces, cuando aparecen estribillos en poemas que no pertenecen al ámbito de la canción? ¿Podemos hablar de estribillo en el sentido auténtico?

El principal problema que se nos plantea aquí tiene que ver con la falta de regularidad de las estrofas, lo que supone desigual periodicidad del estribillo, y afecta a su perceptibilidad. Ocurre en el poema "Platko", de Cal y canto, (Alberti, 1988a: 365-367), dedicado a un jugador de fútbol, donde observamos una repetición con variantes: "no, nadie, nadie, nadie, / nadie se olvida, Platko", que además funciona de cabeza, como en las composiciones populares, pues el poema comienza: "Nadie se olvida, Platko, / no, nadie, nadie, nadie, / oso rubio de Hungría". La aparición tiene todas las características del estribillo: insistencia, creación de ritmo, invitación a la participación coral, y constituye el tema concentrado del poema: la hazaña del portero Platko, que es coreada y merece recuerdo, pero no cumple con el criterio de regularidad y periodicidad, lo cual nos lleva a plantearnos cuáles son los criterios determinantes para considerar a una estructura repetida como estribillo: ¿su función pragmática o semántica?, ¿su forma?, ¿la regularidad? ¿Qué debe primar? ¿Cuáles son los límites?

En el poema "Castigos", de Sobre los ángeles (Alberti, 1988a: 438-439), los conjuntos estróficos formados por versículos se cierran todos con un imperativo: "Oídme", que la primera vez aparece solo y acompañado de reforzadores el resto de las estrofas, excepto la última en la que no aparece el mandato. Por su aparición tras los periodos estróficos y su insistencia enunciativa, cumple los requisitos del estribillo, aunque se niega su carácter coral pues está claro que en el 
imperativo se oye solo la voz del enunciador. Lo que ocurre aquí es que el estribillo pierde todo sentido estructurador y es en realidad una marca de insistencia, de que el discurso continúa: ¿se puede considerar estribillo? Hay que tener en cuenta, por otra parte, que esta aparición está también muy cerca del responsorio y conserva algo de la imploración religiosa.

De distinto carácter es el estribillo que encontramos, también en Sobre los ángeles, en el poema "Invitación al aire" (Alberti, 1988a: 400-401). Aquí al final de cada estrofa, de distinto número de versos, se repite el sintagma "(del / el / sin) aire, aire, aire", como prolongación del verso anterior, que acaba con ese mismo sintagma. Con ello descubrimos una nueva función inédita del estribillo: la de prolongar la estrofa. Desde luego la fórmula tiene una continuidad sintáctica y semántica con lo que le precede, pero comunicativamente vemos que lo único que hace es ofrecer información redundante. Ello tiene que ver con lo absurdo de la estética surrealista, y quizá haya que poner este estribillo junto con los inmotivados y los que buscan la pura sonoridad. Igualmente inmotivado y claro elemento de ruptura es el estribillo formado por una palabra única: "Niño", que aparece después de punto tras cada conjunto estrófico irregular en la segunda parte de "Muerte y juicio" de Sobre los ángeles (Alberti, 1988a: 432-434). El poema habla de la infancia, de la inocencia, de la pérdida de la ingenuidad, pero la aparición aislada de "Niño" deja sin establecer la relación exacta de la palabra con el resto del poema.

Siguiendo con la estética de vanguardia, pero en otra modalidad, tenemos el poema de Gerardo Diego "Barrio" (1989: 146), encabezado por un pareado: "Luz de prendería / para que el alma ría", que se repite idéntico una vez en el desarrollo del poema y que lo cierra con una variante: "Luz de prendería / para que Dios sonría". Aquí el problema, como ocurría en los ejemplos de Alberti, no es la variante, sino la falta de regularidad, que se agrava en este caso porque se pierde todo sentido estrófico, ya que el resto del poema está formado por dísticos y pareados, aunque algunos se pueden asociar por la rima. La pregunta es, entonces: cuando se pierde toda estructura estrófica, ¿podemos seguir hablando de estribillo? 
Algo similar ocurre con el poema de Coro de ánimas, de Diego Jesús Jiménez "Homenaje a don Antonio Machado" (1990: 129-130), en el que, al contrario que en otros poemas del autor, no encontramos división de estrofas, ni siquiera irregulares. El poema consiste en una sola tirada de versos encabezados por la fórmula en cursiva: "Renuncio al testamento / de don Antonio", que se repite cuatro veces más en el poema, una de ellas en el cierre. ¿Podemos considerar esta estructura repetida estribillo? Tiene el sentido de insistencia, condensa parte de la semántica del poema, y, sin embargo, le falta periodicidad regular, con lo que pierde previsibilidad y no da paso a una enunciación coral, pues refleja una postura individual. El hecho de que se presente en cursiva pone de relieve a la vez ese mecanismo de excepción.

Igual que en el poema que acabamos de ver, y en relación con Antonio Machado, Félix Grande, en su libro Música amenazada (1975: 63-65) encabeza el poema "Hoy buscarás en vano" por una cita de Antonio Machado en cursiva "Hoy buscarás en vano / a tu dolor consuelo", versos que, en lugar de repetirse tras cada agrupación estrófica sin regularidad, la encabezan, pues el poema no se cierra con el estribillo. Es, de nuevo, un caso raro en la poesía contemporánea de estribillo ajeno y que hace de cabeza.

Gerardo Diego (1989: 139) abre la sección "Estribillo" de su libro Imagen, a la que más arriba me he referido, precisamente con el poema "Estética", que copia en el lenguaje de vanguardia la esencia de las composiciones con estribillo a la manera tradicional, pues el poema consiste en una fórmula situada al principio y final como marco de un desarrollo:

\section{Estribillo Estribillo Estribillo El canto más perfecto es el canto del grillo}

Destaca, como es propio de la vanguardia, la rima absurda y la falta de coherencia con el resto del poema. Lo mismo ocurre con "Madrigal" (Diego, 1989: 144), de la misma sección, que se abre y se cierra con una variante del mismo tema: "Estabas en el agua / que yo te vi", quedando en el centro un 
desarrollo de esta idea. Vemos, además, en este caso que el tema central guarda cierto aire popular. Aquí no se plantea, en sentido estricto, el problema de la estructura estrófica, pues, como en la poesía popular, la estructura A B A (Estribillo Desarrollo Estribillo) no da ocasión para hablar de un esquema estrófico que se repita o no.

Y no faltan, en la poesía no popularizante no perteneciente a la vanguardia, casos de estribillos que respetan el esquema prototípico, es decir, repetición idéntica tras cada estrofa, aunque las estrofas no sean del repertorio. El poema 19 de la sección "Toro en el mar" de Entre el clavel y la espada (1988b: 105-106), está compuesto por cuatro estrofas con la misma estructura: 14-, 7a, 14-, 14a, 4a, 14a. Los dos últimos versos constituyen el estribillo: "Mis ventanas / ya no dan a los álamos y los ríos de España", siempre separados por un punto y conservando la rima de la estrofa. Se trata de un estribillo donde se concentra la tensión semántica de todo el poema entre la estancia en el destierro francés y la pérdida de los paisajes de España.

En el libro de Luis Rosales Rimas encontramos otros ejemplo similares. En la "Elegía súbita y desamparada en la muerte de D. Ramón Menéndez Pidal” (1996: 280-281) tenemos tres estrofas de diez versos, con mezcla de endecasílabos y heptasílabos, que acaban todas con el estribillo "lo que ha sido raíz tendrá mañana; / hoy todo está más lejos". Se trata de un poema en verso blanco, pero la idea de regularidad y de conexión entre las estrofas y el estribillo es clara.

Nos acercamos con este tipo de repeticiones a una de las funciones originarias que veíamos en el uso del estribillo, la de servir de responsorio en ritos religiosos, que habría que estudiar con más extensión en la poesía de posguerra de carácter religioso o existencial. Traigo aquí dos ejemplos de Luis Rosales. En su primer libro Abril aparece una "Elegía" (1996: 149-150) en verso libre, formada por una reiterada anáfora de "Cuando". Cada tirada estrófica acaba con un penúltimo verso casi similar en todas: "sé tú, llama, nieve + adj.". La intención de marcar final de estrofa es evidente, así como el sentido de letanía que tiene toda la composición, favorecido 
por la anáfora; pero, al no cerrar las estrofa, ¿podemos considerar la expresión que se repite propiamente estribillo?

Este sentido de responsorio aparece en el poema "Misericordia" de Segundo abril (Rosales 1996: 171-174), un extenso poema en versículos amplios y de tono salmódico, en el que tres de las agrupaciones estróficas acaban con "no lloro lo perdido, Señor, nada se pierde". El problema ahora es que el estribillo no se repite en todas las estrofas.

Y acabo con un ejemplo de estribillo sin sentido y puramente fónico en la poesía de vanguardia. Se trata de la traducción que José de Ciria y Escalante (2003: 76) hace del poema "Mutation" de Apollinaire, cuyo estribillo está formado únicamente por las interjecciones "Eh! Oh! Ah!", que aparecen cada dos versos.

\section{7.- Conclusiones}

La muestra que he tomado ha sido limitada, pero me ha permitido esbozar los principales problemas y características que presenta el uso del estribillo en la poesía del siglo $\mathrm{xx}$, a la vez que proponer un esquema semiótico para su estudio. Los conjugación de criterios de diversos niveles de significado para el análisis del estribillo nos puede dar una idea más exacta de la complejidad del fenómeno y sus manifestaciones, sobre todo en esta época de continua renovación poética.

La división entre poesía popularizante y no popularizante parece esencial para el estudio del estribillo en el siglo xx, pues responde a la realidad de distintos patrones estructurales y estéticos en un caso y otro. La poesía que se pretende heredera de las formas del estribillo popular y de las composiciones del siglo XVI y XVII, lo que podemos considerar a grandes rasgos como el género "canción", respeta en general las características formales más externas del estribillo, las que afectan fundamentalmente al plano morfosintáctico, principalmente la repetición periódica en un contexto de arquitectura estrófica regular, pero innovan en otros aspectos, como la relación semántica o pragmática del estribillo con 
el cuerpo de la canción y fundamentalmente tienen una variación mayor en las fórmulas de repetición. También hemos destacado como característica de la modernidad el hecho de que normalmente los estribillos no actúan de cabeza de la pieza y casi nunca están tomados de obras ajenas.

Especialmente interesante resulta para el estudio de la poesía contemporánea la aparición de formas o variantes del estribillo en composiciones cultas que no se presentan continuadoras de la tradición y que no responden al género "canción". Aquí se conservan principalmente los rasgos del estribillo más relacionados con los niveles semánticos y pragmáticos, recogiendo incluso algo de la antigua tradición del responsorio, en algunos casos, pero se rompe con algunos aspectos más formales que van en contra de la previsibilidad del procedimiento, como es la regularidad en la repetición.

\section{Bibliografia}

ALBERTI, Rafael (1988a): Obras completas. Tomo I. Poesía 1920-1938. Madrid: Aguilar.

- (1988b): Obras completas. Tomo II. Poesía 1939-1963, Madrid, Aguilar.

Cancionero de Baena (1851): Madrid: Rivadeneyra.

CERRILLO, Pedro C. (2005): La voz de la memoria (Estudios sobre el Cancionero Popular Infantil). Cuenca: Universidad de Castilla-La Mancha.

-(2007): "Poesía y Escuela: reivindicación de la poesía infantil". Letras Peninsulares, 20.1, pp. 221-241.

CICERÓN (1991): Rhetorica ad Herennium / Retórica a Herenio. Barcelona: Bosch.

CIRIA Y ESCALANTE, José de (2003): Obras. Santander: Universidad de Cantabria.

DARÍO, Rubén (2007): Obras completas I. Poesía. Barcelona: Círculo de lectores / Galaxia Gutenberg.

DIEGO, Gerardo (1989): Obras completas. Tomo I. Poesía. Madrid: Aguilar.

DOMINGUEZ CAPARRÓS, José (2004): Diccionario de métrica española. Madrid: Alianza Editorial. $2^{\mathrm{a}}$ ed. revisada.

FRENK ALATORRE, Margit (1990). Corpus de la antigua lírica popular hispánica (siglos XV a XVII). Madrid: Castalia. $2^{\mathrm{a}}$ ed.

FRYE, Northrop (1991): Anatomía de la crítica. Caracas: Monte Avila.

GARCÍA-PAGE, Mario (2003): "Un fenómeno de repetición textual: el estribillo en Emilio Prados". Estudios de Lingüística de la Universidad de Alicante, 17, pp. 305-328. 
GARCÍA LORCA, Federico (2005): Obras completas I. Barcelona: RBA.

GRANDE, Félix (1975): Antología. Madrid: Editora Nacional.

JIMÉNEZ, Diego Jesús (1990): Poesía. Barcelona: Anthropos.

JIMÉNEZ, Juan Ramón (1999): Diario de una Atlántida. Barcelona: Círculo de Lectores / Galaxia Gutenberg.

JIMÉNEZ PATÓN, Bartolomé (1604): Eloquencia española en arte. Toledo: Thomas de Guzmán.

LAUSBERG, Heinrich (2003): Manual de retórica literaria: fundamentos de una ciencia de la literatura. Madrid: Gredos.

MAYORAL, José Antonio (1994): Figuras retóricas. Madrid: Síntesis.

MÉNDEZ BEJARANO, Mario (1907): La ciencia del verso. Teoría general de la versificación. Madrid: Librería de Victoriano Suárez.

MORIER, Henri (1998): Dictionnaire de Poétique et de Rhétorique. Paris: PUF. 5 e édition revue et augmentée.

OTERO, Blas de (1964): Que trata de España. París: Ruedo Ibérico.

POE, Edgar Allan (2002): La filosofía de la composición y El principio poético. Edición bilingüe. San Lorenzo del Escorial: Libros C. de Langre.

ROSALES, Luis (1996). Obras completas. Volumen I. Poesía: Madrid, Trotta.

SPYROPOULOU LECLANCHE, Maria (1998): Le refrain dans la chanson française de Bruant à Renaud. Limoges: Presses Universitaires de Limoges.

ULLÁN, José-Miguel (2008): Ondulaciones. Barcelona: Círculo de Lectores / Galaxia Gutenberg. 